484 Proceedings of the National Academy of Sciences of Belarus. Biological series, 2019, vol. 64, no. 4, pp. 484-487

ISSN 1029-8940 (Print)

ISSN 2524-230X (Online)

УДК 591.533:595.76:633.853.494

https://doi.org/10.29235/1029-8940-2019-64-4-484-487

Поступила в редакцию 14.11.2018

Received 14.11.2018

\begin{abstract}
Лянь Уян
Научно-практический иентр НАН Беларуси по биоресурсам, Минск, Республика Беларусь

ВИДОВОЙ СОСТАВ ЖЕСТКОКРЫЛЫХ (СОLЕОРТЕRА) НА ПОСЕВАХ ЯРОВОГО РАПСА В БЕЛАРУСИ
\end{abstract}

\begin{abstract}
Аннотация. В результате проведенных исследований выявлен видовой состав жесткокрылых (Coleoptera) на посевах ярового рапса в разные летние месяцы 2016 и 2017 гг. Установлено, что видовое разнообразие жесткокрылых зависит от времени сбора образцов. В 2016 и 2017 гг. на опытных полях обнаружены представители 9 семейств жесткокрылых (блестянки, божьи коровки, быстрянки, скрытники, скрытноеды, мягкотелки, мертвоеды, карапузики и щелкуны), в том числе 27 видов жуков.

Ключевые слова: жесткокрылые, семейство, род, вид, блестянки, божьи коровки

Для цитирования: Лянь Уян. Видовой состав жесткокрылых (Coleoptera) на посевах ярового рапса в Беларуси / Лянь Уян // Вес. Нац. акад. навук Беларусі. Сер. біял. навук. - 2019. - Т. 64, №4. - С. $484-487$. https://doi.org/10.29235/1029-8940-2019-64-4-484-487
\end{abstract}

\title{
Lian Wuyang
}

Scientific and Practical Center for Bioresources of the National Academy of Sciences of Belarus, Minsk, Republic of Belarus

\section{SPECIES COMPOSITION OF BEETLES (COLEOPTERA) ON THE FIELDS OF SPRING RAPE IN BELARUS}

Abstract. It was identified the species composition of beetles (Coleoptera) on the fields of spring rape was revealed in different months of the summer periods of 2016 and 2017. A conclusion is made about the dependence of the species diversity of coleopterans on the collection time of the samples. In 2016 and 2017 years on the experimental fields, representatives of 9 families of Coleoptera were found: sap beetles (Nitidulidae), ladybird beetles (Coccinellidae), antlike flower beetles (Anthicidae), minute scavenger beetles (Latridiidae), silken fungus beetles (Cryptophagidae), soldier beetles (Cantharidae), burying beetles (Silphidae), clown beetles (Histeridae) and click beetles (Elateridae). A total of them were 27 species of beetles.

Keywords: coleoptera, family, genus, species, litters, ladybugs

For citation: Wuyang Lian. Species composition of beetles (Coleoptera) on the fields of spring rape in Belarus. Vestsi Natsyyanal'nai akademii navuk Belarusi. Seryya biyalagichnych navuk = Proceedings of the National Academy of Sciences of Belarus. Biological series, 2019, vol. 64, no. 4, pp. 484-487 (in Russian). https://doi.org/10.29235/1029-8940-2019-64-4-484-487

Введение. Насекомые составляют более 80 \% от всех известных в мире видов животных. Являясь важной частью агроэкосистем, они участвуют в регулировании многих биологических процессов, тесно связанных с функционированием экосистемы.

Биом представляет собой структурную единицу, состоящую из различных биологических популяций в определенном регионе. Изучение сообщества членистоногих - важная составляющая борьбы с вредителями. В агроэкосистеме сообщество членистоногих представлено различными трофическими группами, включающими сапрофагов, фитофагов и зоофагов. Именно зоофаги, в частности жужелицы, являются хищниками и уничтожают вредителей сельхозкультур.

В настоящее время профилактика и борьба с вредителями по-прежнему основываются на применении химических средств. По нашему мнению, в борьбе с вредителями должны применяться биологические методы $[1,2]$. Жужелицы как составная часть зооценоза представляют собой интерес с точки зрения борьбы с вредителями, а изучение их видового состава является важной задачей для проведения биологических методов борьбы [3-5].

Изучение популяционной структуры сообщества членистоногих на посевах рапса проводится в целях обеспечения и осуществления экологического контроля вредителей. Такие исследова-

(C) Уян Лянь, 2019 
ния имеют важное научное и теоретическое значение для выращивания ценных сельскохозяйственных культур.

Цель данной работы - изучение динамики сезонной структуры жесткокрылых на посевах ярового рапса в разные летние месяцы 2016, 2017 гг.

Материалы и методы исследования. Исследования проводили на территории г. П. Прилуки (Минский район) на полях, принадлежащих Институту защиты растений НАН Беларуси. Сезонную динамику активности насекомых изучали в агроценозе ярового рапса. Для отлова активных на поверхности почвы беспозвоночных использовали почвенные ловушки Барбера (в 2016 и 2017 гг. по 20 ловушек соответственно). Время посева ярового рапса на поле 2016 г. - 13 мая, а время сбора - 28 августа. Время посева рапса в 2017 г. - 16 мая, а сбора урожая - 14 сентября.

Результаты и их обсуждение. В летний период с 16 июня по 15 июля 2016 г. на опытном поле обнаружены представители 9 семейств жесткокрылых: блестянки, божьи коровки, быстрянки, скрытники, скрытноеды, мягкотелки, мертвоеды, карапузики и щелкуны. Эти семейства отнесены нами к редким. Представителей этих семейств собрано в общей сложности 47 экз. Блестянки представлены двумя родами - Glischrochilus (Reitter, 1873) и Meligethes (Stephens, 1830), тремя видами - G. grandis (Tournier, 1872), M. aeneus (Fabricius, 1775) и M. denticulatus (Heer, 1841). Быстрянки представлены двумя родами - Anthicus (Paykull, 1798) и Notoxus (Geoffroy, 1762), двумя видами - A. antherinus (Linnaeus, 1760) и N. monoceros (Linnaeus, 1761). Божьи коровки представлены только одним родом - Coccinella (Linnaeus, 1758) и видом C. septempunctata (Linnaeus, 1758). Скрытники представлены двумя родами - Corticarina (Reitter, 1881) и Stephostethus (Le Conte, 1878), двумя видами - C. minuta (Fabricius, 1792) и S. lardarius (De Geer, 1775). Скрытноеды представлены только родом - Atomaria (Stephens, 1829) с одним видом - A. fuscata (Schonherr, 1808). Мягкотелки представлены двумя родами - Ancistronycha (Markel, 1851) и Cantharis (Linnaeus, 1758), двумя видами - A. cyanipennis (Faldermann, 1835), C. rustica (Fallen, 1807). Мертвоеды представлены одним родом - Silpha (Latreille, 1807) и единственным видом - S. obscura (Linnaeus, 1758). Карапузики представлены также одним родом - Margarinotus (Marseul, 1853) и единственным видом - M. ventralis (Marseul, 1854). Щелкуны представлены только родом Agriotes (Eschscholtz, 1829) с одним видом - A. lineatus (Linnaeus, 1767). Среди всех видов доминируют M. aeneus $(38,3 \%)$ и C. septempunctata $(14,9 \%)$.

С 15 июля по 12 августа 2016 г. на опытном поле обнаружены представители 5 семейств: блестянки, божьи коровки, скрытники, скрытноеды и мертвоеды. Представителей этих семейств было собрано в общей сложности 37 экз. Блестянки представлены двумя родами Glischrochilus и Meligethes, двумя видами - G. grandis и M. aeneus. Божьи коровки представлены родом Propylea (Mulsant, 1846) - P. quatuordecimpunctata (Linnaeus, 1758). Скрытники представлены двумя родами - Corticarina и Enicmus (C.G. Thomson, 1859), тремя видами - C. gibbosa (Herbst, 1793) и C. minuta, E. transversus (Olivier, 1790). Скрытноеды представлены тремя родами - Antherophagus (Dejean, 1821), Atomaria u Cryptophagus (Herbst, 1863), четырьмя видами An. pallens (Linnaeus, 1758), At. analis (Erichson, 1846), At. fuscata и C. denticulatus (Heer, 1841). Мертвоеды представлены двумя родами - Nicrophorus (Fabricius, 1775) и Silpha, двумя видами $N$. vespillo (Linnaeus, 1758), S. obscura. Среди всех видов доминируют P. quatuordecimpunctata (16,2 \%), M. aeneus (18,9\%), C. minuta (27\%).

Проведенный анализ популяции жесткокрылых с начале и в конце лета 2016 г. показал, что в течение всего летнего периода доминируют следующие виды семейств: блестянки - 35,7 \%, скрытники - 20,2, божьи коровки - 15,5 \%. Среди видов доминируют M. aeneus $(29,8$ \%) и C. minuta (11,9 \%).

В летний период с 23 июня по 11 августа 2017 г. на опытном поле обнаружены представители 5 семейств: блестянки, скрытники, скрытноеды, мягкотелки и щелкуны. Представителей этих семейств было собрано в общей сложности 66 экз. Блестянки представлены одним родом - Meligethes, тремя видами - M. aeneus, M. ater (Brisout de Barneville, 1863) и M. denticulatus. Скрытники представлены тремя родами - Corticarina, Enicmus и Stephostethus, четырьмя видами - C. Gibbosa, C. minuta, E. transversus и S. lardarius. Скрытноеды представлены двумя родами - Atomaria и Cryptophagus, двумя видами - A. fuscata, C. denticulatus. Мягкотелки представлен только родом Cantharis - C. lateralis (Linnaeus, 1758). Щелкуны представлены двумя родами - Adrastus и Agriotes, тремя видами - Ad. Pallens, Ad. Rachifer и Ag. ustulatus. Среди всех видов доминируют Ad. pallens (21,2\%) и M. aeneus (42,4 \%). 
486 Proceedings of the National Academy of Sciences of Belarus. Biological series, 2019, vol. 64, no. 4, pp. 484-487

С 11 августа по 4 сентября 2017 г. на опытном поле обнаружены представители 5 семейств: блестянки, быстрянки, скрытники, скрытноеды, щелкуны. Представителей этих семейств было собрано в общей сложности 55 экз. Блестянки представлены двумя родами - Glischrochilus и Meligethes, четырьмя видами - G. Grandis, M. aeneus, M. denticulatus и M. flavimanus (Stephens, 1830). Быстрянки представлены только родом Anthicus с единственным видом A. antherinus. Скрытники представлены одним родом - Corticarina, двумя видами - C. gibbosa и C. minuta. Скрытноеды представлены двумя родами - Atomaria и Cryptophagus, двумя видами - A. fuscata, C. denticulatus. Щелкуны представлены двумя родами - Adrastus и Agriotes, двумя видами - Ad. pallens, Ag. ustulatus. Среди всех видов доминируют: C. minuta (14,5\%), C. denticulatus $(21,8 \%)$, M. aeneus $(36,4 \%)$.

Анализ популяции жесткокрылых в начале и в конце лета 2017 г. показал, что в течение всего летнего периода доминируют виды следующих семейств: скрытноеды - 14,9 \%, щелкуны - 17,4, скрытники - 19,8, блестянки - 44,6 \%. Среди всех видов доминируют C. denticulatus (10,7\%), Ad. pallens (11,6 \%) и M. aeneus (39,7\%).

Результаты исследования показали, что количество видов жесткокрылых, собранных в 2016 г., были выше, чем в 2017 г. За весь период исследований доминировал вид Meligethes aeneus - рапсовый цветоед (38 \% от общего количества собранных жесткокрылых (см. таблицу).

Видовой состав жесткокрылых на посевах ярового рапса в 2016 и 2017 гг.

Species composition of beetles on the fields of spring rape in 2016 and 2017

\begin{tabular}{|c|c|c|c|c|c|c|}
\hline \multirow[b]{2}{*}{ Семейство } & \multirow[b]{2}{*}{ Род } & \multirow[b]{2}{*}{ Вид } & \multicolumn{2}{|c|}{2016 г. } & \multicolumn{2}{|c|}{2017 г. } \\
\hline & & & $\begin{array}{c}\text { Июнь- } \\
\text { июль }\end{array}$ & $\begin{array}{l}\text { Июль- } \\
\text { август }\end{array}$ & $\begin{array}{l}\text { Июнь- } \\
\text { август }\end{array}$ & $\begin{array}{l}\text { Август- } \\
\text { сентябрь }\end{array}$ \\
\hline \multirow[t]{5}{*}{ Блестянки } & Glischrochilus & G. grandis & + & + & - & + \\
\hline & \multirow[t]{4}{*}{ Meligethes } & M. aeneus & + & + & + & + \\
\hline & & M. ater & - & - & + & - \\
\hline & & M. denticulatus & + & - & + & + \\
\hline & & M. flavimanus & - & - & - & + \\
\hline \multirow[t]{2}{*}{ Божьи коровки } & Coccinella & C. septempunctata & + & - & - & - \\
\hline & Propylea & P. quatuordecimpunctata & - & + & - & - \\
\hline \multirow[t]{2}{*}{ Быстрянки } & Anthicus & A. antherinus & + & - & - & + \\
\hline & Notoxus & N. monoceros & + & - & - & - \\
\hline \multirow[t]{4}{*}{ Скрытники } & \multirow[t]{2}{*}{ Corticarina } & C. minuta & + & + & + & + \\
\hline & & C. gibbosa & - & + & + & + \\
\hline & Enicmus & E. transversus & - & + & + & - \\
\hline & Stephostethus & S. lardarius & + & - & + & - \\
\hline \multirow[t]{4}{*}{ Скрытноеды } & Antherophagus & An. pallens & - & + & - & - \\
\hline & \multirow[t]{2}{*}{ Atomaria } & A. analis & - & + & - & - \\
\hline & & A. fuscata & + & + & + & + \\
\hline & Cryptophagus & C. denticulatus & - & + & + & + \\
\hline \multirow[t]{3}{*}{ Мягкотелки } & Ancistronycha & A. cyanipennis & + & - & - & - \\
\hline & \multirow[t]{2}{*}{ Cantharis } & C. lateralis & - & - & + & - \\
\hline & & C. rustica & + & - & - & - \\
\hline \multirow[t]{2}{*}{ Мертвоеды } & Necrophorus & N. vespillo & - & + & - & - \\
\hline & Silpha & S. obscura & + & - & - & - \\
\hline Карапузики & Margarinotus & M. ventralis & + & - & - & - \\
\hline \multirow[t]{4}{*}{ Щелкуны } & \multirow[t]{2}{*}{ Adrastus } & Ad. pallens & - & - & + & + \\
\hline & & Ad. rachifer & - & - & + & - \\
\hline & \multirow[t]{2}{*}{ Agriotes } & A. lineatus & + & - & - & - \\
\hline & & Ag. ustulatus & - & - & + & + \\
\hline
\end{tabular}

П р и м е ч а н и е. «+»-есть, «-»-нет. 
Заключение. Таким образом, установлено, что большинство насекомых, собранных во время эксперимента, были фитофагами. За весь период исследований доминировал вид Meligethes aeneus - рапсовый цветоед (38 \% от общего количества собранных жесткокрылых.

\section{Список использованных источников}

1. Бабабекова, Л.А. Сезонная динамика активности почвообитающих насекомых в разных звеньях агробиоценоза / Л. А. Бабабекова, Н. Г. Самедов // Проблемы почвенной зоологии: материалы IV Всесоюз. совещ., Баку, 1972 г. / отв. ред. М.С. Гиляров. - М., 1972. - С. 19.

2. Григорьева, Т. Г. Влияние обработки почвы на фауну пшеничного поля / Т. Г. Григорьева // Проблемы почвенной зоологии: материалы IV Всесоюз. совещ., Баку, 1972 г. / отв. ред. М. С. Гиляров. - М., 1972. - С. 42.

3. Бельская, Е.А. Жужелицы в агроценозе яровой пшеницы на юге свердловской области и влияние некоторых средств химизации на их популяции / Е. А. Бельская, Е. В. Зиновьев, М. А. Козырев // Экология. - 2002. № 1. - С. 42-49.

4. Блинцов, А.И. Изменение почвенной мезофауны под влиянием инсектицидов / А.И. Блинцов // Проблемы почвенной зоологии: тез. докл. VII Всесоюз. совещ. (Киев, 1981 г.) / отв. ред. В. Г. Долин. - Киев, 1981. - С. 33-34.

5. Добровольский, Б. В. Решение проблемы защиты растениеводства СССР от проволочников / Б. В. Добровольский // Почвенная фауна и почвенное плодородие: тр. 9-го Междунар. коллоквиума по почв. зоологии, Москва, 1620 авг. 1985 г. / отв. ред. Б. Р. Стриганова. - М., 1987. - С. 310-311.

\section{References}

1. Bababekova L. A., Samedov N. G. Seasonal dynamics of activity of soil-inhabiting insects in different links of agrobiocenosis. Problemy pochvennoi zoologii: materialy IV vsesoyuznogo soveshchaniya (Baku, 1972 god) [Problems of soil zoology: materials of the IV All-Union Conference (Baku, 1972)]. Moscow, 1972, p. 19 (in Russian).

2. Grigoryeva T.G. Effect of soil cultivation on the wheat field fauna. Problemy pochvennoi zoologii: materialy IV vsesoyuznogo soveshchaniya (Baku, 1972 god) [Problems of soil zoology: materials of the IV All-Union conference (Baku, 1972)]. Moscow, 1972, p. 42 (in Russian).

3. Belskaya E. A., Zinovev E. V., Kozyrev M.A. Carabids in a spring wheat agrocenosis to the south of Sverdlovsk oblast and the effect of insecticide treatment on their populations. Ekologiya [Ecology], 2002, no. 1, pp. 42-49. https://doi. org/10.1023/A:1013671722178 (in Russian).

4. Blintsov A. I. Changes in soil mesofauna under the influence of insecticides. Problemy pochvennoi zoologii: tezisy dokladov VII Vsesoyuznogo soveshchaniya (Kiev, 1981 god) [Problems of soil zoology: Abstracts of the VII All-Union conference (Kiev, 1981)]. Kiev, 1981, pp. 33-34 (in Russian).

5. Dobrovolsky B. V. Solution of the problem of protecting the plant growing of the USSR from wireworms. Pochvennaya fauna i pochvennoe plodorodie: trudy 9-go Mezhdunarodnogo kollokviuma po pochvennoi zoologii (Moskva 16-20 avgusta 1985 goda) [Soil fauna and soil fertility: works of the Ninth International colloquium on soil zoology (Moscow, August 16-20, 1985)]. Moscow, 1987, pp. 310-311 (in Russian).

\section{Информация об авторе}

Лянь Уян - аспирант. Научно-практический центр НАН Беларуси по биоресурсам (ул. Академическая, 27, 220072, г. Минск, Республика Беларусь). E-mail: 1053776457@qq.com

\section{Information about the author}

Lian Wuyang - Postgraduate student. Scientific and Practical Center for Bioresources of the National Academy of Sciences of Belarus (27, Akademicheskaya Str., 220072, Minsk, Republic of Belarus). E-mail: 1053776457@qq.com 